Research Article

\title{
Sources of Nitrogen Pollution in Upstream of Fenhe River Reservoir Based on the Nitrogen and Oxygen Stable Isotope
}

\author{
Ying Zhao $\mathbb{D},^{1}$ Jinhua Dang $\mathbb{D}{ }^{1}$ and Fei Wang $\mathbb{D}^{2,3}$ \\ ${ }^{1}$ Shanxi Academy of Environmental Sciences, Taiyuan, Shanxi 030027, China \\ ${ }^{2}$ School of Life Science, Shanxi University, Taiyuan, Shanxi 030006, China \\ ${ }^{3}$ School of Physical Education, Shanxi University, Taiyuan 030006, China \\ Correspondence should be addressed to Fei Wang; nemo@sxu.edu.cn
}

Received 8 November 2019; Revised 3 February 2020; Accepted 8 February 2020; Published 31 March 2020

Guest Editor: Chenglian Feng

Copyright ( $\odot 2020$ Ying Zhao et al. This is an open access article distributed under the Creative Commons Attribution License, which permits unrestricted use, distribution, and reproduction in any medium, provided the original work is properly cited.

Identification of nitrate sources is important for the management of rivers. In this study, stable isotopes $\left(\delta^{15} \mathrm{~N}\right.$ and $\left.\delta^{18} \mathrm{O}\right)$ and a Bayesian model (stable isotope analysis in R, SIAR) were applied to identify nitrate sources and estimate the proportional contributions of multiple nitrate sources in the upstream of Fenhe River Reservoir that serves as a source of drinking water in Shanxi Province of North China. The results showed that the $86.4 \%$ of total nitrogen (TN) concentrations in the water samples exceeded the guided values of the Chinese Surface Water Environmental Quality Standard (GB 3838-2002). The influent of tributary and discharges of sewage caused the severe nitrogen pollution. SIAR was used to estimate the proportional contribution of three nitrate sources (sewage, inorganic fertilizer, and soil nitrogen). It was revealed that domestic sewage was the dominant nitrate source, and the contributions were $33 \%-41 \%$. The contributions of inorganic fertilizer and soil to nitrogen load were $30 \%-$ $31 \%$ and $31 \%-37 \%$, respectively. Therefore, the pollution sources of nitrogen can be determined more accurately if the rules of sewage discharges are considered.

\section{Introduction}

As an important life element, nitrogen is the main substance used for protein synthesis during phytoplankton growth. However, water eutrophication that was caused by nitrogen and other nutrients and its harm to aquatic ecosystems have become one of the key issues of concern to society $[1,2]$. Nitrate is the main form of nitrogen contaminants that occur in freshwater bodies. In recent years, the excessive use of agricultural fertilizers, the discharge of large amounts of domestic sewage, and animal manure have caused the nitrate content in freshwater bodies to be abnormally high, which poses a potential threat to the health of humans $[3,4]$. In order to control the nitrogen source pollution in water bodies, identification of the pollution load caused by different sources of pollution that enter the water bodies is considered as an effective approach to help prevent and address the pollution in water bodies [5].
With the rapid development of isotope technology, nitrogen and oxygen isotope techniques $\left(\delta^{15} \mathrm{~N}\right.$ and $\left.\delta^{18} \mathrm{O}\right)$ are often used to determine the source of nitrate in the water body. Quantitative studies on nitrogen from different sources are carried out using mathematical models. Some frequently employed models include the stable isotope mixture model, a Bayesian model (stable isotope analysis in $\mathrm{R}, \mathrm{SIAR}$ ), and IsoSource model. Parnell et al. [6] established the SIAR mixture model, which used a logical priori distribution of the Dirichlet distribution established via the Bayesian framework, according to the estimated probability of the contribution rate of each source in the mixture. The model, which has been successfully applied to the analysis of nitrate sources, considered the identification of more potential sources of pollution and reduced the uncertainty of the mass mixture model. For example, it has been conducted to identify the contribution rate of different sources of nitrate nitrogen in a subtropical watershed, the groundwater, 
the rainfall runoff, the river, as well as in the Three Gorges Reservoir of China [3, 7-10].

As the largest reservoir in Shanxi Province, the Fenhe River Reservoir is also the biggest centralized drinking water source in Taiyuan. The reservoir is located in the upstream section of the mainstream of the Fenhe River and has a drainage basin area of $5,268 \mathrm{~km}^{2}$. At present, the daily domestic water supply in Taiyuan is about $600,000 \mathrm{~m}^{3} / \mathrm{d}$, accounting for $43 \%$ of the total water supply. The Fenhe River Reservoir is a river-type reservoir, in which water is mainly replenished by the upstream river, and the Yellow River Transfer Project accounts for about $45 \%$ of the replenished water. This study analyzes the source of nitrates and explores the possible migration and transformation of nitrogen by analyzing the nitrogen and oxygen isotope characteristics in the water bodies. The contribution rates of nitrogen sources are estimated based on the SIAR mass mixture model. The results will facilitate the water quality control and the effective use of water resources for improved tracing and quantitation of nitrogen pollution sources in the surface water environment.

\section{Materials and Methods}

2.1. Study Area. The upstream of Fenhe River Reservoir has a total length of 216 kilometers and a drainage basin area of $7750 \mathrm{~km}^{2}$. The Fenhe River Reservoir covers an area of $5268 \mathrm{~km}^{2}$, belonging to Ningwu county, Jingle county, Lan county, and Loufan county, which accounts for $78.6 \%$ of the total area of four counties. The length of mainstream for the upper course of Fenhe River Reservoir is $122 \mathrm{~km}$, and 13 tributaries are included. Each area of Honghe River, Dongnian River, Lanhe River, and Jianhe River, which were defined as the first level branches, is more than $500 \mathrm{~km}^{2}$. The study area has four distinctive seasons, with an average temperature and relative humidity of $7.2^{\circ} \mathrm{C}$ and $60.1 \%$. About 180-200 days in the year are frost-free. The distribution of precipitation is $465 \mathrm{~mm}$, which occurred mostly from July to September. Thus, its wet season is defined between July and September, while the dry season is from November to March of the next year.

2.2. Sample Collection and Measurement. Water samples were collected at 13 sampling points in the Fenhe River Reservoir and the upstream section of the river. The specific layout and positions are shown in Figure 1. The sampling time of the wet and dry seasons is in the periods of August $21^{\text {st }}-25^{\text {th }}$ and November $15^{\text {th }}-19^{\text {th }}$, respectively. As the aim of this study was to explore the sources of nitrogen pollution, we set the sampling sites mainly considering the influent pollutants to Fenhe River based on the state controlling sites. According to previous site investigation, there was nitrogen pollution in the middle section, and the sampling sites were less correspondingly.

The collected water samples were stored separately in $500 \mathrm{~mL}$ polyethylene bottles that were prerinsed with distilled water and were then put into a portable incubator for temporary storage. The water temperature $(\mathrm{T}), \mathrm{pH}$, electric conductivity (ORP), and dissolved oxygen (DO) in the water body were measured using a portable water quality parameter tester and a portable acidometer.

The collected water samples were returned to the laboratory on the same day of collection, and $150 \mathrm{~mL}$ of water samples was taken and filtered with the quantitative filter paper to measure the $\mathrm{TN}$, ammonium $\left(\mathrm{NH}_{4}^{+}-\mathrm{N}\right)$, nitrate nitrogen $\left(\mathrm{NO}_{3}^{-}-\mathrm{N}\right)$, and nitrite $\left(\mathrm{NO}_{2}^{-}-\mathrm{N}\right)$. These parameters were analyzed according to standard methods approved by the National Environmental Protection Agency of China [11]. TN in the digestion was measured by the alkaline potassium persulfate ultraviolet spectrophotometry. $\mathrm{NH}_{4}^{+}-\mathrm{N}$ was determined by the Nesslerization colorimetric method. $\mathrm{NO}_{3}^{-}-\mathrm{N}$ was measured by the phenol disulfonic acid ultraviolet spectrophotometric method. The concentration of $\mathrm{NO}_{2}^{-}-\mathrm{N}$ was measured by the $\mathrm{N}$-(1-naphthyl) -ethylenediamine spectrophotometry.

The measurement of nitrogen and oxygen isotopes was conducted in the Third Oceanographic Research Institute of the Oceanic Bureau by applying MAT 253 Isotope Ratio Mass Spectrometry (Thermo Scientific Corporation). The detection process for the machine is as follows: the PAL autosampler is first used to automate sample injection, and then the $\mathrm{N}_{2} \mathrm{O}$ in the sample is frozen and fixed by the primary cold trap in the liquid nitrogen tank. After 10 minutes, the primary cold trap leaves the liquid nitrogen tank, and the frozen and fixed $\mathrm{N}_{2} \mathrm{O}$ is released to the secondary cold trap in the liquid nitrogen tank. After another 5 minutes, the secondary cold trap leaves the liquid nitrogen tank. The $\mathrm{N}_{2} \mathrm{O}$ is separated from other impurity gases via a chromatographic column (with a column temperature of $45^{\circ} \mathrm{C}$ ). The separated $\mathrm{N}_{2} \mathrm{O}$ is transferred into the Mat 253 detector via helium gas. Under the high-energy electron impact ionization and accelerating field, the gaseous ions with different mass-to-charge ratios $(\mathrm{m} / z 44, \mathrm{~m} / z 45$, and $\mathrm{m} /$ $z 46)$ enter the magnetic field and are separated into different ion beams. The ion beams then enter the receiver and are converted to the electric signal to measure the nitrogen to oxygen isotope ratio [12]. The values of $\delta^{15} \mathrm{~N}$ and $\delta^{18} \mathrm{O}$ were obtained by referring to the international standards of atmospheric nitrogen (AIR) and standard mean ocean water (SMOW), respectively. The analysis precision for the values of $\delta^{15} \mathrm{~N}$ and $\delta^{18} \mathrm{O}$ was \pm 0.2 and $\pm 0.3 \%$, respectively, which can meet the precision requirements for the study.

2.3. The Model of Isotope Source Analysis. In this study, the SIAR isotope source analytical model was used to calculate the contribution rate of each $\mathrm{N}$ source. Assuming that there are $\mathrm{N}$ measured values, J isotopes, and $\mathrm{K}$ nitrogen sources, the SIAR model can be expressed as follows:

$$
\begin{aligned}
X_{i j} & =\sum_{k-1}^{k} P_{k}\left(S_{j k}+C_{j k}\right)+\varepsilon_{i j}, \\
S_{j k} & \sim N\left(\mu_{j k}, \omega_{j k}^{2}\right), \\
C_{j k} & \sim N\left(\lambda_{j k}, \tau_{j k}^{2}\right), \\
\varepsilon_{j k} & \sim N\left(0, \sigma_{j}^{2}\right),
\end{aligned}
$$



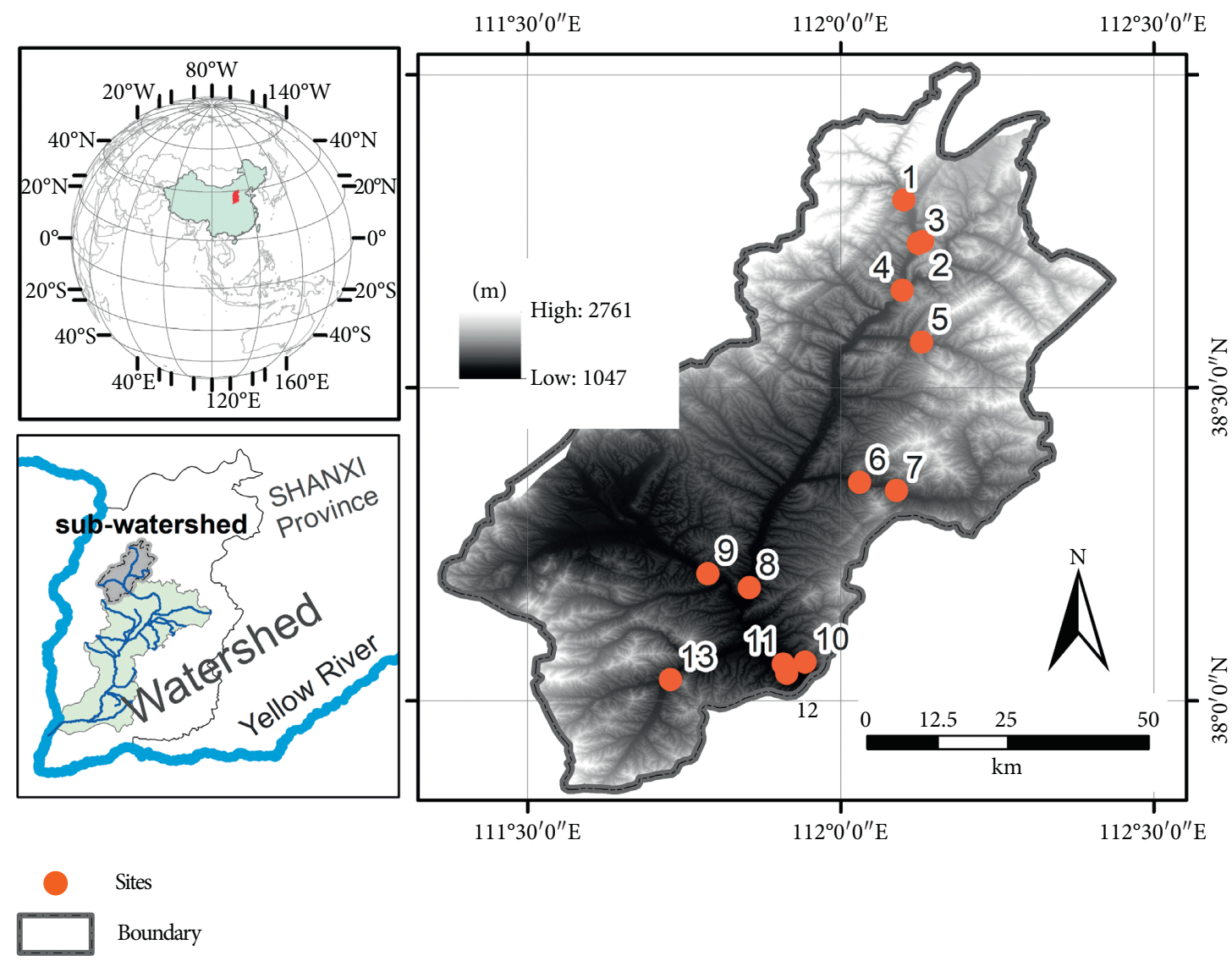

FIgURE 1: Locations of the sampling sites in study area. S1: Leiming Temple; S2: the entrance to Yellow River water diversion junction of Toumaying village; S3: the outlet of Yellow River water diversion junction of Toumaying village; S4: the junction of Honghe River; S5: Mingshuihe River; S6: Jingle county; S7: Dongnianhe River; S8: Hecha village; S9: Quli county; S10: the inlet of Fenhe Reservoir; S11: the middle part of Fenhe Reservoir; S12: the outlet of Fenhe Reservoir; S13: Jianhe River Bridge.

where $X_{i j}$ is the ratio of the isotope $i$ in the mixture $j(i=1,2$, $3, \ldots, N ; j=1,2,3, \ldots, J), P_{k}$ is the contribution rate of source $k(k=1,2,3, \ldots, K), S_{j k}$ is the rate of isotope $j$ in source $k$ $(k=1,2,3, \ldots, K), \mu$ is the average value, $\omega$ is the standard deviation, $C_{j k}$ is the fractionation coefficient of the $j_{\text {th }}$ isotope on the $k_{\mathrm{th}}$ source, $\lambda$ is the average value, $\tau$ is the standard deviation, $\varepsilon_{j k}$ is the residual error, and $\delta$ is the standard deviation.

\section{Results and Discussion}

3.1. Nitrogen Pollution in the Upstream Section of the Fenhe River Reservoir. As shown in Table 1, in the wet period, water temperature ranged from $11^{\circ} \mathrm{C}$ to $25.2^{\circ} \mathrm{C}, \mathrm{pH}$ was 7.83-8.85, DO concentrations were between $4.9 \mathrm{mg} / \mathrm{L}$ and $12.5 \mathrm{mg} / \mathrm{L}$, and ORP values were $201-263 \mathrm{mv}$. However, in the dry period, $\mathrm{pH}$ and $\mathrm{DO}$ values were almost the same as that in the wet period. However, the values of temperature and ORP were lower than that in flood season.

The distribution of different forms of inorganic nitrogen during four seasons in the Fenhe River is shown in Figure 2. It can be seen that the concentrations of $\mathrm{TN}, \mathrm{NH}_{4}^{+}-\mathrm{N}$, $\mathrm{NO}_{3}^{-}-\mathrm{N}$, and $\mathrm{NO}_{2}^{-}-\mathrm{N}$ during the wet season were $0.88-3.52$, $0.035-0.187,0.16-1.06$, and $0.008-0.174 \mathrm{mg} \cdot \mathrm{L}^{-1}$, respectively. During the dry seasons, the concentrations of TN,
$\mathrm{NH}_{4}{ }^{+}-\mathrm{N}, \quad \mathrm{NO}_{3}{ }^{-}-\mathrm{N}$, and $\mathrm{NO}_{2}{ }^{-}-\mathrm{N}$ were 0.87-10.6, $0.079-0.129,0.28-3.01$, and $0.006-0.838 \mathrm{mg} \cdot \mathrm{L}^{-1}$, respectively. Figure 2 shows that $84.6 \%$ of the sampling points in the upstream of the Fenhe River Reservoir exceeded the guided values of Class III (TN for $1.0 \mathrm{mg} \cdot \mathrm{L}^{-1}$ ) referred by Chinese Surface Water Environmental Quality Standard (GB 3838-2002) [13].

The peaks of inorganic nitrogen concentration occurred frequently at the three sampling points of S6, S8, and S9. The concentrations of the $\mathrm{NH}_{4}{ }^{+}-\mathrm{N}$ and $\mathrm{NO}_{2}{ }^{-}-\mathrm{N}$ in S6 were relatively high, and the concentrations of the $\mathrm{TN}$ and $\mathrm{NO}_{3}{ }^{-}-\mathrm{N}$ in $\mathrm{S} 8$ reached the highest level in the wet season. As these two sampling points are located in the mainstream of the Fenhe River, the pollution was mainly from the domestic pollution caused by the untreated sewage in 13 towns along the mainstream of the Fenhe River. The concentrations of the $\mathrm{TN}$ and $\mathrm{NO}_{3}{ }^{-}-\mathrm{N}$ at $\mathrm{S} 9$ were both relatively high during the wet and dry seasons. This sampling point, which was mainly affected by the tributary of the Lan River, may suffer from the incomplete treatment of the surrounding sewage treatment plants and the discharge of domestic sewage. At the sampling point $\mathrm{S} 13, \mathrm{NH}_{4}{ }^{+}-\mathrm{N}$ and $\mathrm{NO}_{3}{ }^{-}-\mathrm{N}$ were relatively high during the wet season. It was found that the surrounding population density was relatively dense, and a large amount of domestic sewage and livestock manure were 
TABle 1: Chemical indices in the water samples collected from the upstream of Fenhe River.

\begin{tabular}{|c|c|c|c|c|c|c|c|c|}
\hline \multirow{2}{*}{ Sampling sites } & \multicolumn{4}{|c|}{ Wet period } & \multicolumn{4}{|c|}{ Dry period } \\
\hline & $\mathrm{T}\left({ }^{\circ} \mathrm{C}\right)$ & $\mathrm{pH}$ & DO (mg/L) & ORP (mv) & $\mathrm{T}\left({ }^{\circ} \mathrm{C}\right)$ & $\mathrm{pH}$ & DO $(\mathrm{mg} / \mathrm{L})$ & ORP (mv) \\
\hline S1 & $12.0 \pm 0.6$ & $8.23 \pm 0.40$ & $5.8 \pm 0.3$ & $257 \pm 12$ & $10.1 \pm 0.5$ & $8.52 \pm 0.44$ & $8.8 \pm 0.4$ & $164 \pm 9$ \\
\hline S2 & $13.0 \pm 0.7$ & $8.12 \pm 0.41$ & $11.2 \pm 0.6$ & $241 \pm 13$ & $15.5 \pm 0.9$ & $8.4 \pm 0.40$ & $16.5 \pm 0.9$ & $178 \pm 9$ \\
\hline S3 & $11.0 \pm 0.5$ & $8.51 \pm 0.39$ & $8.3 \pm 0.4$ & $253 \pm 12$ & $12.0 \pm 0.6$ & $8.73 \pm 0.43$ & $15.3 \pm 0.8$ & $187 \pm 10$ \\
\hline S4 & $14.0 \pm 0.7$ & $8.42 \pm 0.44$ & $5.5 \pm 0.3$ & $263 \pm 13$ & $18.1 \pm 0.9$ & $8.86 \pm 0.46$ & $12.3 \pm 0.6$ & $155 \pm 8$ \\
\hline S5 & $19.0 \pm 1.03$ & $8.25 \pm 0.38$ & $8.3 \pm 0.4$ & $254 \pm 13$ & $19.7 \pm 0.9$ & $7.83 \pm 0.37$ & $10.8 \pm 0.6$ & $155 \pm 8$ \\
\hline S6 & $19.0 \pm 0.90$ & $8.36 \pm 0.41$ & $12.5 \pm 0.7$ & $249 \pm 11$ & $18.5 \pm 0.9$ & $8.47 \pm 0.42$ & $6.84 \pm 0.4$ & $175 \pm 10$ \\
\hline S7 & $17.1 \pm 0.86$ & $8.35 \pm 0.41$ & $6.8 \pm 0.4$ & $201 \pm 9$ & $16.9 \pm 0.9$ & $8.48 \pm 0.39$ & $8.69 \pm 0.4$ & $170 \pm 8$ \\
\hline S8 & $14.0 \pm 0.71$ & $8.35 \pm 0.47$ & $5.5 \pm 0.3$ & $249 \pm 12$ & $18.1 \pm 1.0$ & $8.63 \pm 0.48$ & $6.38 \pm 0.3$ & $189 \pm 10$ \\
\hline S9 & $18.0 \pm 0.83$ & $7.83 \pm 0.41$ & $4.9 \pm 0.2$ & $252 \pm 14$ & $21.3 \pm 1.0$ & $8.07 \pm 0.41$ & $5.02 \pm 0.3$ & $161 \pm 8$ \\
\hline S10 & $25.2 \pm 1.30$ & $8.54 \pm 0.44$ & $9.7 \pm 0.5$ & $222 \pm 12$ & $23.5 \pm 1.3$ & $8.2 \pm 0.39$ & $10.8 \pm 0.5$ & $205 \pm 10$ \\
\hline S11 & $23.3 \pm 1.14$ & $8.51 \pm 0.40$ & $9.5 \pm 0.5$ & $234 \pm 12$ & $23.2 \pm 1.1$ & $8.63 \pm 0.43$ & $10.6 \pm 0.6$ & $248 \pm 13$ \\
\hline S12 & $23.6 \pm 1.10$ & $8.58 \pm 0.43$ & $8.6 \pm 0.5$ & $234 \pm 11$ & $22.9 \pm 1.2$ & $8.95 \pm 0.46$ & $12.5 \pm 0.6$ & $249 \pm 12$ \\
\hline S13 & $21.3 \pm 1.12$ & $8.85 \pm 0.47$ & $7.3 \pm 0.4$ & $246 \pm 11$ & $19.8 \pm 0.9$ & $8.85 \pm 0.47$ & $5.17 \pm 0.2$ & $184 \pm 10$ \\
\hline
\end{tabular}

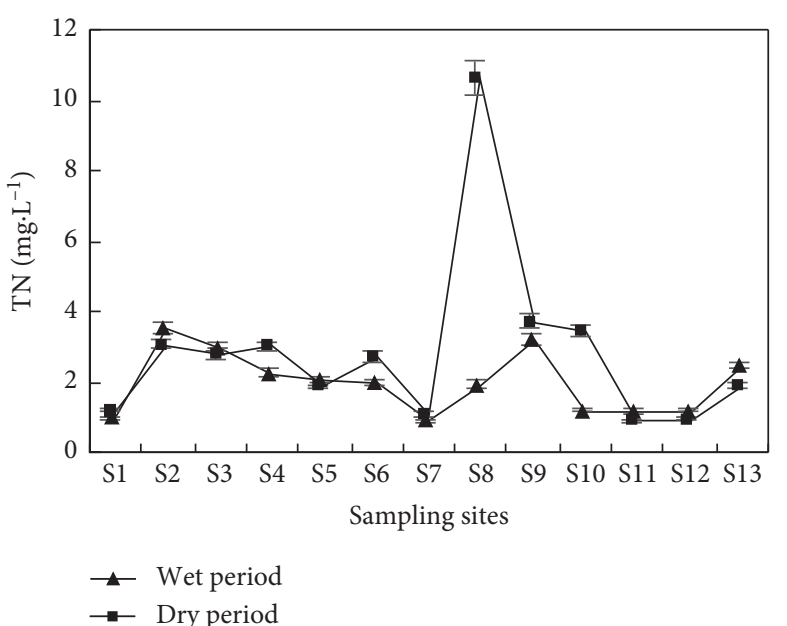

(a)

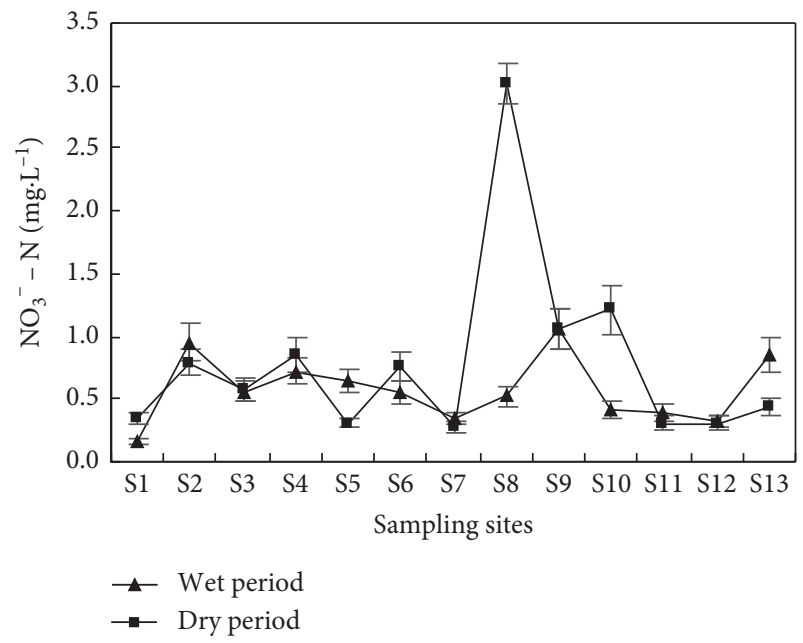

(c)

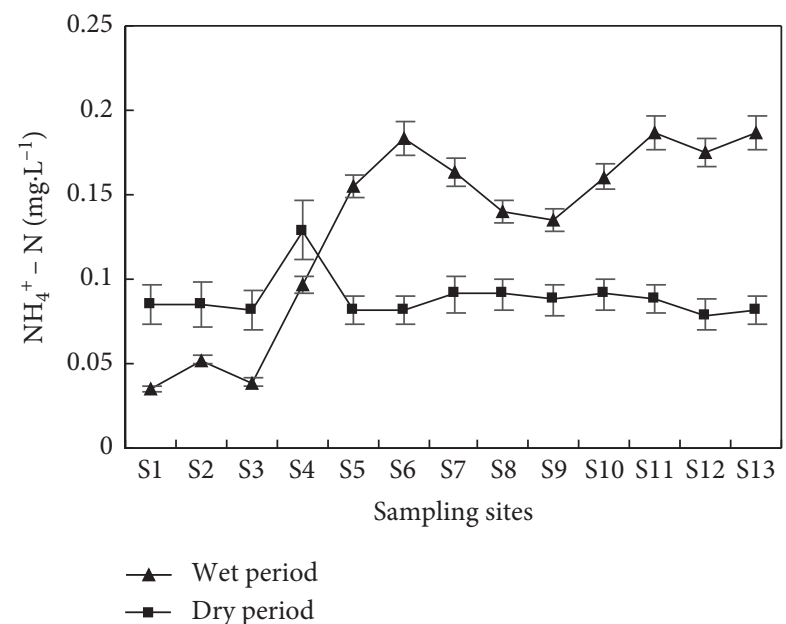

(b)

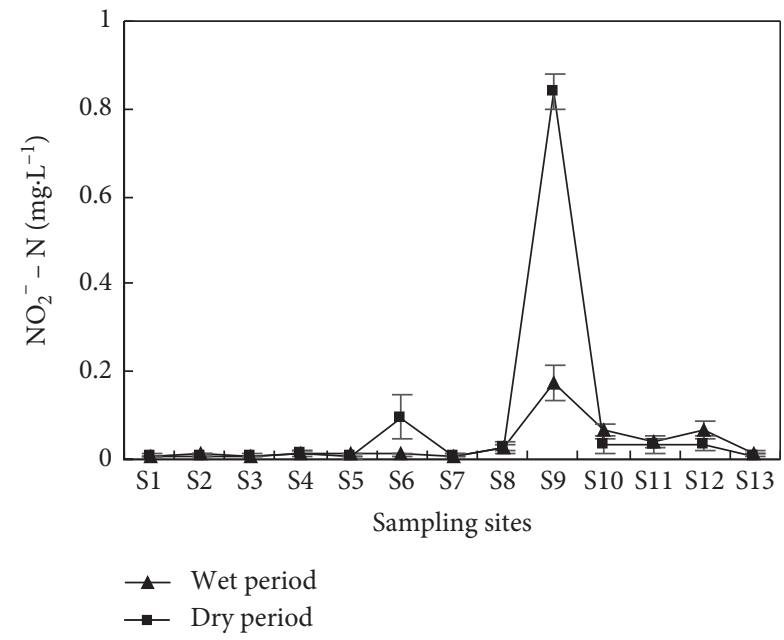

(d)

FIgURE 2: Distribution characteristics of different forms of inorganic nitrogen in study area.

directly discharged into the river without any treatment. Our previous studies also showed that the highest TN concentrations in three monitoring points of the Fenhe River
Reservoir exceeded the standard values for Class III of Chinese water quality grade scale $\left(1.0 \mathrm{mg} \cdot \mathrm{L}^{-1}\right)$ by 3.61 times [13]. In 2015, the concentrations of TN during the flood 
season and dry season were $1.40-1.42 \mathrm{mg} / \mathrm{L}$ and $2.48-2.98 \mathrm{mg} / \mathrm{L}$, respectively, with the TN exceeding the standard value by $1.8-4.9$ times. More than $90 \%$ of the monitoring points in the upstream section of the Fenhe River Reservoir have been comprehensively polluted.

\subsection{Characteristics of Nitrate Isotopes in the Upstream Section} of the Fenhe River Reservoir. When using nitrate nitrogen and oxygen isotopes to identify nitrate sources in rivers, it is assuming that the nitrate nitrogen is stable in the water body. However, denitrification may change the composition of nitrate source isotopes that further affect the traceability. Therefore, understanding the existence of denitrification is a prerequisite for exploring the source of nitrate [5]. Studies have shown that if the ratio of $\delta^{15} \mathrm{~N}$ to $\delta^{18} \mathrm{O}$ is $1.3: 1-2.1: 1$, denitrification can take place [14]. In addition, when the DO concentrations in the water body exceeds $3.1 \mathrm{mg} \cdot \mathrm{L}^{-1}$, it is not conducive to have denitrification [15]. In this study, the DO content in each sampling point was greater than $3.1 \mathrm{mg} \cdot \mathrm{L}^{-1}$ during the entire sampling period, and the DO content was sufficient (Table 1). Additionally, the linear proportional relationship in the range of $1.3: 1-2.1: 1$ was absent for the ratio of $\delta^{15} \mathrm{~N}$ to $\delta^{18} \mathrm{O}$. Thus, it can be determined that almost no denitrification occurred in the Fenhe River.

The results of nitrate nitrogen and oxygen isotope showed that $\delta^{15} \mathrm{~N}$ during the wet season was $0.117-4.894 \%$, while $\delta^{18} \mathrm{O}$ during the wet season was from -3.268 to $24.531 \%$ (Figure 3). During the dry season, $\delta^{15} \mathrm{~N}$ was within $0.527-4.691 \%$, while $\delta^{18} \mathrm{O}$ was in the range of $-0.485-21.527 \%$. The mean nitrate $\delta^{15} \mathrm{~N}$ during the wet and dry seasons was 2.283 and $2.710 \%$, respectively. The values of $\delta^{15} \mathrm{~N}$ in S9 and S5 were the lowest, whereas the values of $\delta^{15} \mathrm{~N}$ in $\mathrm{S} 10$ and S11 were the highest probably because the reservoir is located near Lan County that has a dense population. Therefore, S10 and S11 were more affected by domestic discharged sewage. The mean nitrate $\delta^{18} \mathrm{O}$ during the wet and dry seasons was 5.862 and $5.891 \%$, respectively, and the samples with the highest values were all collected from the Jianhe River Bridge at the sampling point S13, indicating that the pollution caused by inorganic fertilizer was relatively severe at $\mathrm{S} 13$.

For the pollution sources of $\mathrm{NO}_{3}^{-}$, the fertilizer source indicated the inorganic nitrogen in the fertilizer spread to river by precipitation or infiltration. Previous studies reported that $\delta^{15} \mathrm{~N}$ values in fertilizers vary between $-6 \%$ and $6 \%$, while $\delta^{18} \mathrm{O}$ values range from 17 to $25[16] . \mathrm{NO}_{3}{ }^{-}-\mathrm{N}$ derived from soil organic $\mathrm{N}$ is a product of bacterial decomposition of organic materials originated from degradation of plants and animal wastes [17]. The $\delta^{15} \mathrm{~N}$ values in soils (mostly organic $\mathrm{N}$ ) frequently range from $-3 \%$ to $8 \%$, and the $\delta^{18} \mathrm{O}$ values range from 17 to 25 [18]. Atmospheric $\mathrm{N}$ is reported to be enriched in $\delta^{18} \mathrm{O}-\mathrm{NO}_{3}{ }^{-}$by exchanging $\mathrm{O}$ atoms with ozone. Literature reported that the $\delta^{15} \mathrm{~N}$ values in the atmospheric deposition range from $-13 \%$ to $13 \%$, and the $\delta^{18} \mathrm{O}$ values range from $29 \%$ to $58.2 \%$ o $[19,20]$. The $\delta^{15} \mathrm{~N}$ values of $\mathrm{NO}_{3}{ }^{-}-\mathrm{N}$ derived from manure and waste water generally range from $4 \%$ to $25 \%$, and the corresponding $\delta^{18} \mathrm{O}$ values vary between $-5 \%$ and $10 \%$ o $[21,22]$.
As shown in Figure 4, the concentrations of $\delta^{15} \mathrm{~N}$ and $\delta^{18} \mathrm{O}$ values at the sampling points of this study mainly distributed in the range of typical values of inorganic fertilizer, soil organic nitrogen, and domestic sewage area or nearby. Combining the site-investigation results of pollution sources, it can be confirmed that the nitrate nitrogen pollution in the upstream section of the Fenhe River Reservoir mainly came from the inorganic fertilizer, soil organic nitrogen, and domestic sewage.

\subsection{Calculating the Contribution Rate for Each Source of $\mathrm{NO}_{3}{ }^{-}$} by SIAR Model in the Upstream of the Fenhe River Reservoir. In this study, the isotope source analytical model SIAR based on Bayesian analysis was used to analyze the contribution rates of the three nitrate nitrogen sources to the upstream of the Fenhe River Reservoir. The mean isotope characteristics and variance of the three sources of pollution were derived from local sampling data. The former analysis indicated that the microbial denitrification in study area was weak. Therefore, the fractionation coefficient $C_{j k}$ in equation (1) was assumed to be zero.

According to the output of the SIAR model, the contribution rates of the three sources of $\mathrm{NO}_{3}^{-}$in the upstream section of the Fenhe River Reservoir during the wet season were in the following order, i.e., soil organic nitrogen $(36.83 \%)>$ domestic sewage $(32.96 \%)>$ inorganic fertilizer $(30.21 \%)$. For the following dry season, however, the following order was observed as domestic sewage (40.68\%)> soil organic nitrogen $(31.40 \%)>$ inorganic fertilizer $(27.91 \%)$ (Figure 5). The results showed that the soil nitrogen contributed a higher rate to nitrate during the wet season. It was because that the land-use types in the upstream section of the Fenhe River Reservoir in 2019 mainly consisted of farmlands, forests, and grasslands, accounting for 33.2, 30.2, and $33.1 \%$ of the total land area, respectively. Water-soluble organic nitrogen in the forest soil often plays an important role in the soil nitrogen pool. For many forests, the watersoluble organic nitrogen levels in soil are more than 100 times than the levels of $\mathrm{NH}_{4}{ }^{+}-\mathrm{N}$ and $\mathrm{NO}_{3}{ }^{-}-\mathrm{N}[23,24]$. In this study, the rainfall was so high during the wet season that the water-soluble organic nitrogen entered the reservoir with water and soil loss. Then, they were converted to nitrate by nitrification. The contribution of domestic sewage to nitrate nitrogen was as high to $41 \%$ during the dry season due to the increased human activities on harvest during this period. However, the contribution of inorganic fertilizers was small $(28-31 \%)$ in two periods. It can be seen that the project of "Five Water Treatment" in Shanxi Province has achieved initial success, and the nonpoint source pollution caused by planting is controlled. However, the control of rural and urban sewage discharge still needs to be further improved.

The above results were different from that reported in a subtropical watershed located in Changxing County, Zhejiang Province, by Yang et al. [7]. Their studies showed that the contribution rate of sources of manure sewage and atmospheric deposition in December was higher than that in May, while the contribution rate of sources of chemical fertilizer and soil in May was higher than that in December. 


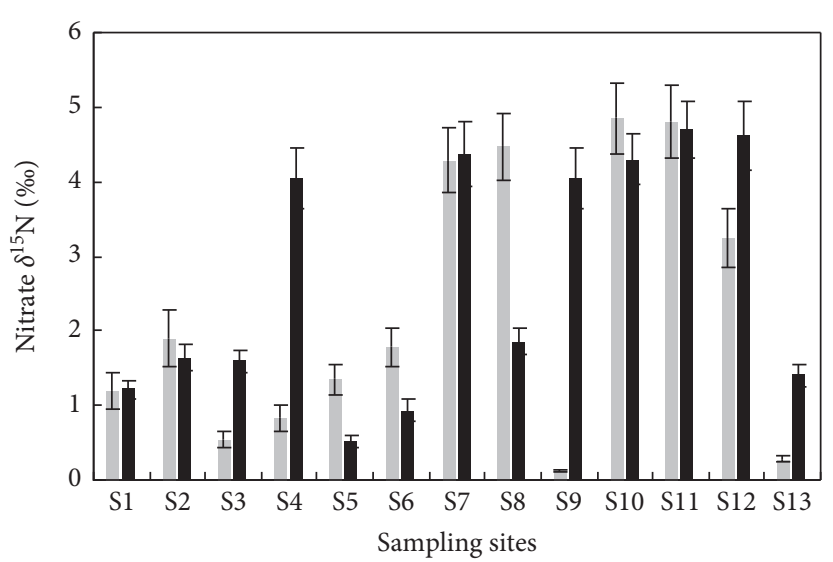

Wet period

- Dry period

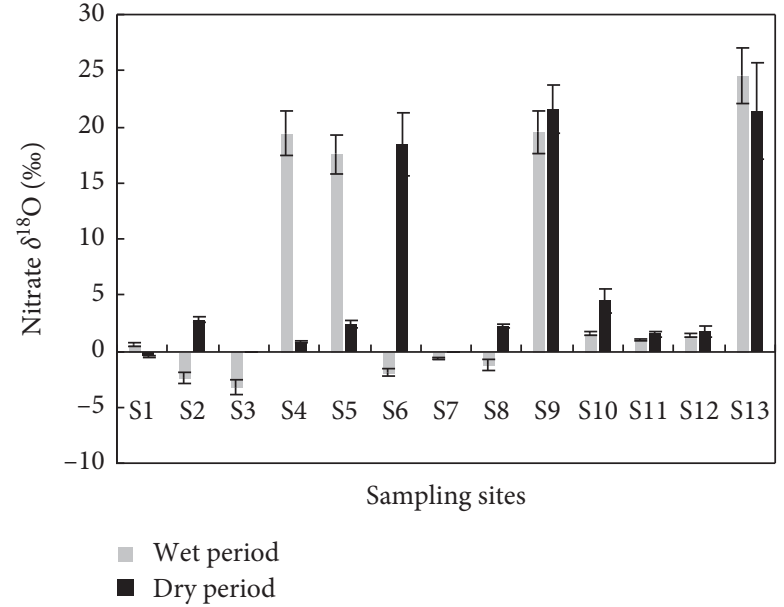

(b)

FIGURE 3: Distribution characteristics of nitrogen and oxygen isotope in the study area.

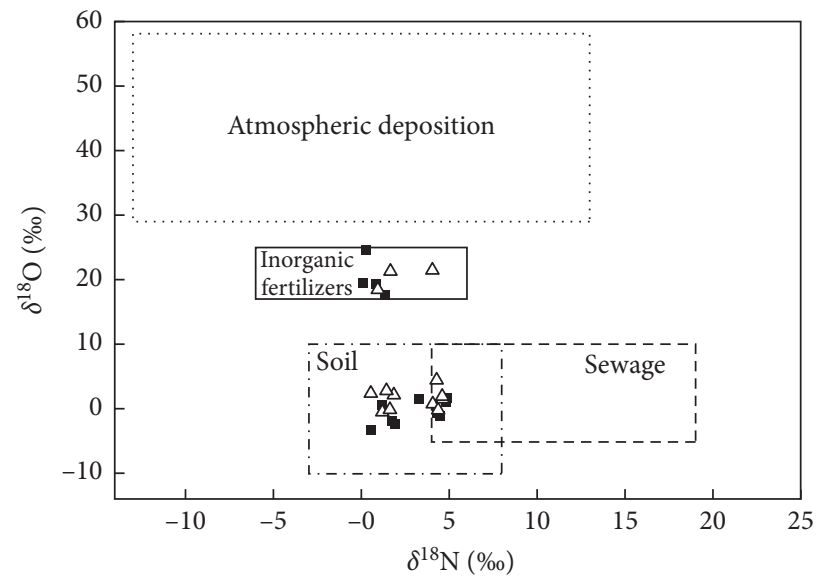

- Wet period

$\Delta$ Dry period

Figure 4: Distribution of typical and measured values of $\delta^{15} \mathrm{~N}$ and $\delta^{18} \mathrm{O}$ for different sources of the nitrate.

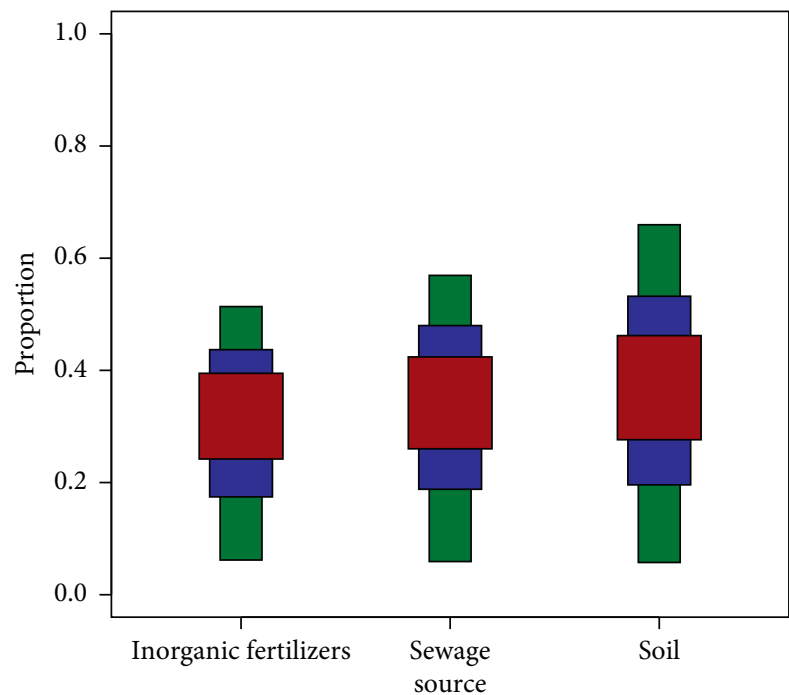

(a)

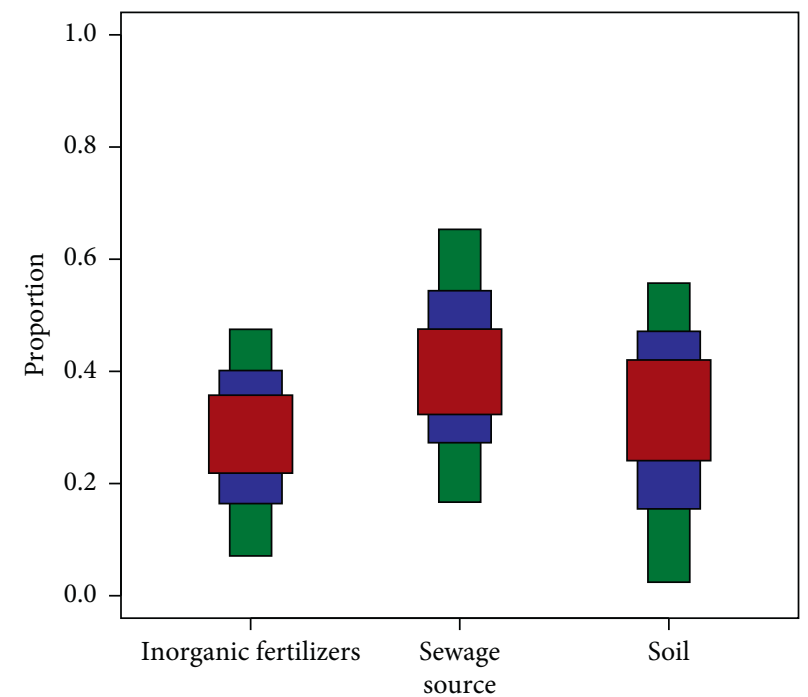

(b)

FIgURe 5: Box plots of mean probability estimates of the source contributions in the upstream of Fenhe Reservoir: (a) wet period; (b) dry period. Note: the legends of green, blue, and red referred to $50 \%, 75 \%$, and $95 \%$ credibility interval, respectively. 


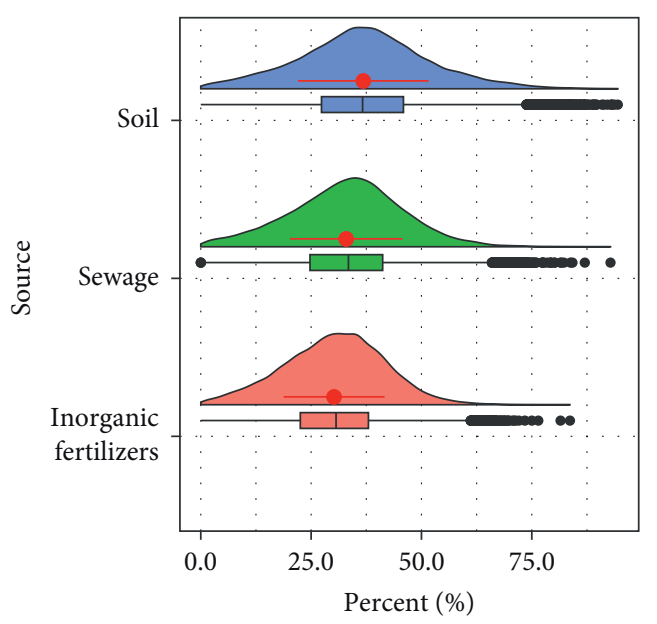

(a)

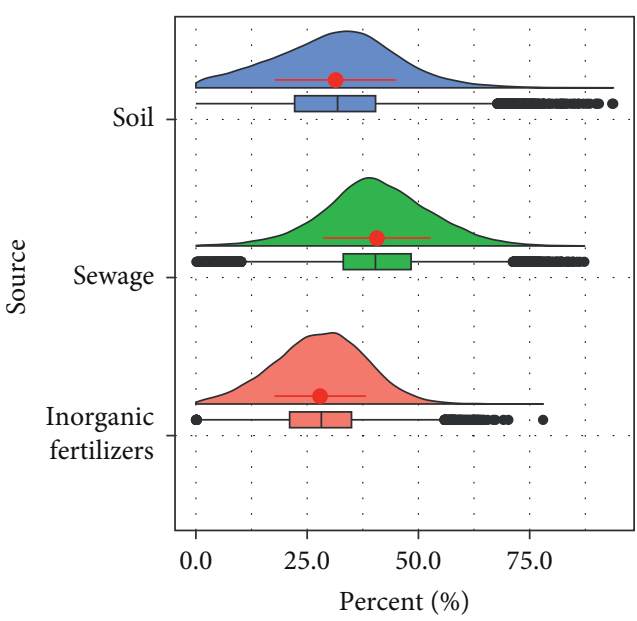

(b)

Figure 6: Posterior distribution of proportional contributions of three potential $\mathrm{NO}_{3}^{-}$sources in the upstream of Fenhe Reservoir: (a) wet period; (b) dry period.

In December, the contribution rate of manure sewage is the highest, reaching $61 \%$. In May, the contribution rate of fertilizer is the highest at $37 \%$. The reasons may be related with two effects. The wet season was defined as in May, and the fertilizer is also applied in this month shortly before rice is transplanted into the field. While in Fenhe River, the wet season was in August so that the effect of fertilizer on nitrogen pollution was slight. In the watershed of Changxing County, as the $\mathrm{N}$ isotope signature of sewage is similar to $\mathrm{N}$ isotope signature of manure (mainly animal waste), these two sources were treated as one source. However, in Fenhe River, the sewage source of nitrogen pollution only indicated domestic sewage, and the manure source was not included.

To further explain the contribution of the SIAR model to each pollution source, this study provided a post hoc testing distribution diagram (Figure 6). It showed that the median, mean, and maximum posterior probabilities for different nitrate nitrogen sources were generally identical, and the post hoc probabilities were symmetrically distributed. For the posterior samples of the three nitrate nitrogen sources, their sums of the post hoc mean, median, and maximum estimated probabilities were all equal to 1 .

\section{Conclusions}

(1) The section with severe nitrogen pollution in the study area was mainly affected by the input of tributaries and the discharge of surrounding domestic sewage. The water quality during the wet season was better than that in the dry season. In sum, the water quality in study area was severely contaminated.

(2) Quantitative analysis of the nitrogen and oxygen isotope of nitrate in the water body based on the SIAR model showed that the inorganic fertilizer, soil organic nitrogen, and domestic sewage were the main sources of pollution in the upstream section of the Fenhe River Reservoir. The contribution rate of chemical fertilizers, soil organic nitrogen, and domestic sewage was $30-31 \%, 31-37 \%$, and $33-41 \%$, respectively. It was seemed that their contributions were not so far different. It may be related with the function of Fenhe River Reservoir. As the Fenhe River Reservoir is the biggest centralized drinking water source in Taiyuan, the pollution sources from industry were scare. Thus, the contributions from agricultural, domestic pollution, and soil were main pollution sources.

To establish goals of reducing nitrogen pollution in Fenhe River, a proposal was made for the development of a nitrogen control program that consists of the following elements: regulation of industrial discharges of sewage to the greatest extent practicable, reduction of rural domestic discharges from diffuse sources into the upper Fenhe River, improving the system of municipal wastewater treatment, and maintenance of a viable research program to seek maximum efficiency and effectiveness in the control of nitrogen introductions into the Fenhe River.

In this study, the SIAR model was used to study quantitatively the contribution rate of nitrate sources in the upstream section of the Fenhe River Reservoir. However, some limitations need to be considered. During the migration and transformation of water nitrogen, the nitrification and denitrification can cause the fractionation of nitrogen, which may, in turn, affect the contents of $\delta^{15} \mathrm{~N}$ and $\delta^{18} \mathrm{O}$. In this study, $C_{j k}$ was defined as 0 and the fractionation was neglected, which may lead to the deviations of the calculation. In future studies, the effect of the isotope fractionation should be incorporated in the SIAR model to more accurately track and quantify the nitrogen pollutants.

\section{Data Availability}

The data used to support the findings of this study are available from the corresponding author upon request. 


\section{Conflicts of Interest}

The authors declare that they have no conflicts of interest.

\section{Acknowledgments}

This research was financially supported by the National Natural Science Foundation of China (no. 41601202), the Natural Science Foundation of Shanxi Province (nos. 201801D121261 and 201701D121116), and the Key Research and Development Project of Shanxi Province (nos. 201803D221002-4 and 201903D321069).

\section{References}

[1] J. N. Galloway, A. R. Townsend, J. W. Erisman et al., "Transformation of the nitrogen cycle: recent trends, questions, and potential solutions," Science, vol. 320, no. 5878, pp. 889-892, 2008.

[2] C. Wu, C. Maurer, Y. Wang, S. Xue, and D. L. Davis, "Water pollution and human health in China," Environmental Health Perspectives, vol. 107, no. 4, pp. 251-256, 1999.

[3] Y. Zhao, B. Zheng, H. Jia, and Z. Chen, "Determination sources of nitrates into the Three Gorges Reservoir using nitrogen and oxygen isotopes," Science of the Total Environment, vol. 687, pp. 128-136, 2019.

[4] Z. Chen, J. Chen, H. Li et al., "Sources of nitrate in Xiangshan Bay (China), as identified using nitrogen and oxygen isotopes," Estuarine, Coastal and Shelf Science, vol. 207, pp. 109-118, 2018.

[5] I. Paredes, F. Ramírez, M. G. Forero, and A. J. Green, "Stable isotopes in helophytes reflect anthropogenic nitrogen pollution in entry streams at the Doñana World Heritage Site," Ecological Indicators, vol. 97, pp. 130-140, 2019.

[6] A. Parnell, R. Inger, S. Bearhop et al., SIAR: Stable Isotope Analysis in R, 2008.

[7] L. Yang, J. Han, J. Xue et al., "Nitrate source apportionment in a subtropical watershed using Bayesian model," Science of the Total Environment, vol. 463-464, pp. 340-347, 2013.

[8] I. Matiatos, "Nitrate source identification in groundwater of multiple land-use areas by combining isotopes and multivariate statistical analysis: a case study of Asopos basin (Central Greece)," Science of the Total Environment, vol. 541, pp. 802-814, 2016.

[9] Z. Jin, Q. Zheng, C. Zhu, Y. Wang, J. Jiarong, and F. Li, "Contribution of nitrate sources in surface water in multiple land use areas by combining isotopes and a Bayesian isotope mixing model," Applied Geochemistry, vol. 93, pp. 10-19, 2018.

[10] C. Gong, C. Xian, Y. Su, and Z. Ouyang, "Estimating the nitrogen source apportionment of Sophora japonica in roadside green spaces using stable isotope," Science of The Total Environment, vol. 689, pp. 1348-1357, 2019.

[11] Ouyang, Analyzing Method for Water and Waste Water, 3rd edition, Environmental Science Press, Beijing, China, 2002, in Chinese.

[12] M. R. Mcilvin, M. A. Altabet, and A. Chem, "Chemical conversion of nitrate and nitrite to nitrous oxide for nitrogen and oxygen isotopic analysis in freshwater and seawater," Analytical Chemistry, vol. 77, no. 17, pp. 5589-5595, 2005.

[13] SEPAC (State Environmental Protection Administration of China), Environmental Quality Standard for Surface Water,
China (GB3838-2002), China Environmental Science Press, Beijing, China, 2002, in Chinese.

[14] A. Amberger and H.-L. Schmidt, "Natürliche Isotopengehalte von Nitrat als Indikatoren für dessen Herkunft," Geochimica et Cosmochimica Acta, vol. 51, no. 10, pp. 2699-2705, 1987.

[15] L. A. Desimone and B. L. Howes, "Nitrogen transport and transformations in a shallow aquifer receiving wastewater discharge: a mass balance approach," Water Resources Research, vol. 34, no. 2, pp. 271-285, 1998.

[16] Y.-Y. Yang and G. S. Toor, " $\delta 15 \mathrm{~N}$ and $\delta 18 \mathrm{O}$ reveal the sources of nitrate-nitrogen in urban residential stormwater runoff," Environmental Science \& Technology, vol. 50, no. 6, pp. 2881-2889, 2016.

[17] O. Nikolenko, A. Jurado, A. V. Borges, K. Knöller, and S. Brouy $\square$ re, "Isotopic composition of nitrogen species in groundwater under agricultural areas: a review," Science of the Total Environment, vol. 621, pp. 1415-1432, 2018.

[18] J. Ding, B. Xi, R. Gao et al., "Identifying diffused nitrate sources in a stream in an agricultural field using a dual isotopic approach," Science of the Total Environment, vol. 484, pp. 10-18, 2014.

[19] C. Kendall, E. M. Elliott, and S. D. Wankel, "Tracing anthropogenic inputs of nitrogen to ecosystems," inStable Isotopes in Ecology and Environmental Science, R. H. Michener, K. Lajtha, Eds., pp. 375-449 Blackwell Publishing, London, UK, 2007.

[20] A. Nestler, M. Berglund, F. Accoe et al., "Isotopes for improved management of nitrate pollution in aqueous resources: review of surface water field studies: review of surface water field studies," Environmental Science and Pollution Research, vol. 18, no. 4, pp. 519-533, 2011.

[21] J. C. Finaly, R. W. Sterner, and S. Kumar, "Isotopic evidence for in lake production of accumulating nitrate in lake superior," Ecological Application, vol. 17, no. 8, pp. 2323-2332, 2007.

[22] H. D. Freyer, "Seasonal variation of ${ }^{15} \mathrm{~N} /{ }^{14} \mathrm{~N}$ ratios in atmospheric nitrate species," Tellus Series B: Chemical \& Physical Meteorology, vol. 43, no. 1, pp. 30-44, 2002.

[23] K. Kalbitz, S. Solinger, J.-H. Park, B. Michalzik, and E. Matzner, "Controls on the dynamics of dissolved organic matter in soils: a review," Soil Science, vol. 165, no. 4, pp. 277-304, 2000.

[24] J.-S. Wu, P.-K. Jiang, S. X. Chang, Q.-F. Xu, and Y. Lin, "Dissolved soil organic carbon and nitrogen were affected by conversion of native forests to plantations in subtropical China," Canadian Journal of Soil Science, vol. 90, no. 1, pp. 27-36, 2010. 